\title{
LIDAR OBSERVATION CAMPAIGN OF SUGAR CANE FIRES AND INDUSTRIAL EMISSIONS IN THE STATE OF SÃO PAULO, BRAZIL.
}

\author{
E. Landulfo ${ }^{a}$, Maria Paulete M.P. Jorge ${ }^{b}$, Gerhard Held ${ }^{c}$, Roberto Guardani ${ }^{d}$, Juliana \\ Steffens $^{d}$, Sergio dos Anjos F. Pinto ${ }^{e}$, Iara R. Andre ${ }^{e}$, Gilberto Garcia ${ }^{e}$, F.J.S. Lopes ${ }^{a}$, \\ Glauber L. Mariano ${ }^{b}$, Renata F. da Costa ${ }^{a}$, Patricia F. Rodrigues ${ }^{a}$ \\ ${ }^{a}$ IPEN-CNEN/SP, Av. Lineu Prestes 2242, São Paulo, SP, Brazil; \\ ${ }^{b}$ INPE-CPTEC, Av. dos Astronautas, 1.758, São Jose dos Campos, SP, Brazil; \\ ${ }^{c}$ IPMET-UNESP, Av. Luis Edmundo Carrijo Coube 14-01, Bauru, SP, Brazil; \\ ${ }^{d}$ CEPEMA-USP, Rodovia Cônego Domenico Rangoni Km 270, Cubatão, SP, Brazil; ${ }^{e}$ \\ CEAPLA-UNESP, Av. 24A 1515, Rio Claro, SP, Brazil;
}

\begin{abstract}
Brazil has an important role in the biomass burning, with the detection of approximately 100,000 burning spots in a single year (2007). Most of these spots occur in the southern part of the Amazon basin during the dry season (from August to november) and these emissions reach the southeast of the country, a highly populated region and with serious urban air pollution problems. With the growing demand on biofuels, sugarcane is considerably expanding in the state of São Paulo, being a strong contributor to the bad air quality in this region. In the state of São Paulo, the main land use are pasture and sugarcane crop, that covers around $50 \%$ and $10 \%$ of the total area, respectively. Despite the aerosol from sugarcane burning having reduced atmospheric residence time, from a few days to some weeks, they might get together with those aerosol which spread over long distances (hundreds to thousands of kilometers). In the period of June through February 2010 a LIDAR observation campaign was carried in the state of São Paulo, Brazil, in order to observe and characterize optically the aerosols from two distinct sources, namely, sugar cane biomass burning and industrial emissions. For this purpose 2 LIDAR systems were available, one mobile and the other placed in a laboratory, both working in the visible $(532 \mathrm{~nm})$ and additionally the mobile system had a Raman channel available $(607 \mathrm{~nm})$. Also this campaign counted with a SODAR, a meteorological RADAR specially set up to detect aerosol "echoes" and gas-particle analyzers. To guarantee a good regional coverage 4 distinct sites were available to deploy the instruments, 2 in the near field of biomass burning activities (Rio Claro and Bauru), one for industrial emissions (Cubatão) and others from urban sources (São Paulo). The whole campaign provide the equivalent of 30 days of measurements which allowed us to get aerosol optical properties such as backscattering/extinction coefficients, scatter and LIDAR ratios, those were used to correlate with air quality and meteorological indicators and quantities. In this paper we should focus on the preliminary results of the Raman LIDAR system and its derived aerosol optical quantities.
\end{abstract}

Keywords: LIDAR, aerosols, scatter ratio, lidar ratio, biomass burning

\section{INTRODUCTION}

The direct radiative forcing estimated for biomass-burning aerosols was revised due to their strong influence over the clouds. ${ }^{1}$ Brazil has an important role in the biomass burning, with the detection of approximately 100,000 active fires in 2007, according to CPTEC/INPE (www.cptec.inpe.br \queimadas). The biomass burning includes the burning of forests, savannas, and agricultural land. In Brazil, the Northeast and Southeast regions are of great importance to the emission of aerosols due to the burning of sugarcane crops made in a programmed way.

In the last decades a great number of studies about biomass burning was carried out mainly on the physical (direct ${ }^{2-4}$ and indirect effects ${ }^{5,6}$ ) and chemical properties. ${ }^{7,8}$ In terms of air quality biomass burning is a major

Further author information: (Send correspondence to E.L.)

E.L.: E-mail: elandulf@ipen.br, Telephone: 5511 3133-9372

Lidar Technologies, Techniques, and Measurements for Atmospheric Remote Sensing VI,

edited by Upendra N. Singh, Gelsomina Pappalardo, Proc. of SPIE Vol. 7832, 78320I

(c) 2010 SPIE - CCC code: 0277-786X/10/\$18 - doi: 10.1117/12.866078

Proc. of SPIE Vol. 7832 78320I-1 


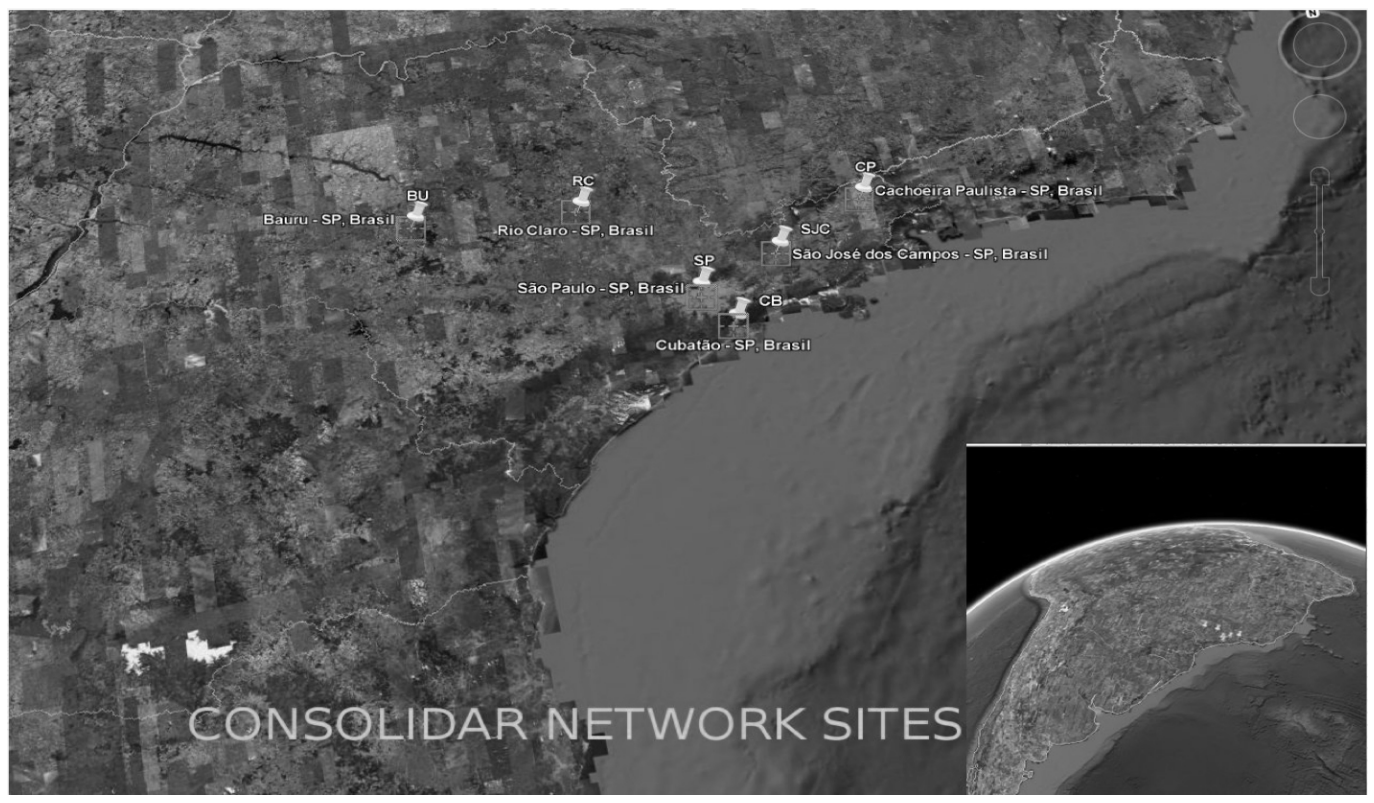

Figure 1. Map displaying the sites used in the measuring campaign as part of the CONSOLIDAR network.

source of air pollution and the second largest source of anthropogenic aerosols, ${ }^{2}$ specifically in Brazil, it is possible to highlight several studies referring to: gases, ${ }^{9,10}$ trace gases transport ${ }^{11}$ particulate matter composition, ${ }^{10}$ effects on diffuse and photossinthetically active radiation, ${ }^{12}$ cloud physics, ${ }^{13}$ satellite measurements ${ }^{14}$ and air masses trajectories. ${ }^{15,16}$

In Brazil, up to date, few studies using lidar were made concerning biomass burning. Landulfoet al. ${ }^{17}$ using an elastic lidar showed the presence of highly absorbent particles, characteristic of biomass burning aerosol. In this study four-day air mass backtrajectories analysis and satellite data showed that the aerosol originated from Amazon regions. The optical depth measured by the Sunphotometer also indicated the presence of biomass burning coming from these distant regions. Despite the average value for LR around 45 sr (typical of urban environment), studies indicate that the presence of dust and biomass burning aerosol transported from great distances $^{18}$ away from São Paulo city increases the suspended atmospheric aerosol variability where normally the layer between $1-3 \mathrm{~km}$ is responsible for $20-25 \%$ of all the tropospheric aerosol amount. ${ }^{19}$ The purpose of this paper was to study the influence of aerosol from biomass burning on the aerosol loading over the city of São Paulo, Brazil during the Brazilian dry season of 2007.

Herein a multi-sited approach was employed, using active a lidar system in 5 different sites, namely, São Paulo, Cubatão, Rio Claro and Bauru. These sites belong to the so-called CONSOLIDAR network and their locations are given in Figure 1 The entire campaign spanned from June 2009 through November 2009, in order to observe and characterize optically the aerosols from two distinct sources, that is, sugar cane biomass burning and industrial emissions. For this purpose a mobile LIDAR system was available, working in the visible (532 $\mathrm{nm})$ and additionally the mobile system had a Raman channel available $(607 \mathrm{~nm})$. Also in this campaign we counted with a SODAR, a meteorological RADAR specially set up to detect aerosol "echoes" and gas-particle analyzers their correlated data should be covered in the near future in a more detailed paper. The good regional coverage displayed 4 distinct sites where the instruments were deployed, 2 in the near field of biomass burning activities (Rio Claro and Bauru), one for industrial emissions (Cubatão) and others from urban sources (São Paulo). The whole campaign provided the equivalent of 30 days of measurements which allowed us to get aerosol optical properties such as backscattering $\backslash$ extinction coefficients, scatter and LIDAR ratios, those were used to correlate with air quality and meteorological indicators and quantities. Thus we could try to extract a regional signature among different aerosol typed sites and from the obtained aerosol optical data and try to correlate them with specific sites in terms of these data. 


\section{EQUIPMENT DESCRIPTION}

\subsection{LIDAR SET-UP}

The lidar system employed in the campaign is a single-wavelength backscatter system pointing vertically to the zenith and operating in the biaxial mode. The light source is based on a commercial Nd:YAG laser (CFR 200 by Quantel SA) operating at the second harmonic frequency (SHF), at $532 \mathrm{~nm}$, with a fixed repetition rate of 20 Hz. The emitted laser pulses have a divergence of less than $0.5 \mathrm{mrad}$ after expansion $(4 \times)$. A $20 \mathrm{~cm}$ diameter telescope $(\mathrm{F} \#=4.5)$ is used to collect the backscattered laser light. The telescope's field of view (FOV) is variable (1-2 mrad) by using a small diaphragm. The lidar is currently used with a fixed FOV, which permits a full overlap between the telescope FOV and the laser beam at heights around $180 \mathrm{~m}$ above the lidar system. This FOV value, in accordance with the detection electronics, permits the probing of the atmosphere up to the free troposphere $(12-15 \mathrm{~km}$ asl.).

The backscattered laser radiation is then sent to 2 photomultiplier tubes (PMT) coupled to a narrowband (1 $\mathrm{nm}$ FWHM) interference filters to assure the reduction of the solar background during daytime operation and to improve the signal-to-noise ratio (SNR) at altitudes greater than $3 \mathrm{~km}$. The PMT output signal is recorded by a Transient Recorder in both analog and photoncounting mode. Data are averaged between 2 and 5 min and then summed up over a period of about $30 \mathrm{~min}-1 \mathrm{~h}$, with a typical spatial resolution of $7.5 \mathrm{~m}$, which corresponds to a $100 \mathrm{~ns}$ temporal resolution. For the Raman channel at $607 \mathrm{~nm}$ longer integration times are applied.

The LIDAR systems, LR101-V-D200, summarized features are shown in the table 1below:

Table 1. LIDAR SYSTEM FEATURES

\begin{tabular}{|c|c|}
\hline \hline SYSTEM FEATURES & LR101-V-D200 \\
\hline \hline \hline LASER Energy/pulse & up to 130 mJ \\
\hline \hline TELESCOPE Config. & Cassegranian \\
\hline \hline TELESCOPE Diam. & $200 \mathrm{~mm}$ \\
\hline \hline TELESCOPE F \# & 4.5 \\
\hline \hline DETECTION Channels & $532 \mathrm{~nm}$ and $607 \mathrm{~nm}$ \\
\hline
\end{tabular}

\section{METHODOLOGY}

The mobile lidar system was deployed in 4 different sites during the period of June 2009 through November 2009. The sites and period of each sub-campaign is given in Table 2.

Table 2. LIDAR CAMPAIGN PERIODS

\begin{tabular}{|c|cc|}
\hline \hline SITE & PERIOD & TOTAL DAYS OF MEAS. \\
\hline \hline \hline São Paulo & April - June 2009 & 12 \\
\hline \hline Cubatão & November 2009 & 22 \\
\hline \hline Rio Claro & June - October 2009 & 41 \\
\hline \hline Bauru & February 2010 & 5 \\
\hline \hline
\end{tabular}

\subsection{Elastic Channel}

From the elastic channel, namely the $532 \mathrm{~nm}$, one could retrieve the Aerosol Scattering Ratio $S R$ and the aerosol backscattering coefficient profile, $\beta(r)$.

$$
A S R=\frac{\beta^{a}(\lambda, r)+\beta^{m}(\lambda, r)}{\beta^{m}(\lambda, r)}
$$


Where $\beta^{a}(\lambda, r)$ is the aerosol backscattering coefficient at a given wavelength and height, $\lambda, r$, and $\beta^{m}(\lambda, r)$ is the molecular backscattering coefficient, which could be parametrized form a standard atmosphere or when available from a sounding retrieval.

The aerosol backscattering profile could be retrieved by solving the Lidar equation using a Klett like algorithm $^{20}$.

$$
P(\lambda, R)=P_{L}\left(\frac{c \tau}{2}\right) \frac{\beta(\lambda, R) A_{0} \xi(\lambda) \zeta(R)}{R^{2}} \exp \left[-2 \int_{0}^{R} \alpha(\lambda, r) r\right]
$$

where, $\mathrm{P}(\lambda, \mathrm{R})$ is the lidar signal received from a distance $\mathrm{R}$ at the wavelength $\lambda, P_{L}$ is the emitted laser power, $A_{0}$ is the telescope receiving area, $\xi(\lambda)$ is the receiver's spectral transmission factor, $\beta(\lambda, R)$ is the atmospheric volume backscatter coefficient, $\zeta(R)$ is the overlap factor between the FOV of the telescope and the laser beam, $\alpha(\lambda, R)$ is the extinction coefficient, $c$ is the light speed and $\tau$ is the laser pulse length. In this calculation one has to assume the ratio $\frac{\alpha(\lambda, r)}{\beta(\lambda, r)}$ as known and this quantity could be retrieved form the Raman channel as shown below in the next section.

\subsection{Raman Channel}

For the calculation of aerosol backscattering and extinction profiles from elastic and Raman backscatters the traditional formulas from ${ }^{21}$ we calculated the aerosol extinction and backscattering coefficient from the elastic $532 \mathrm{~nm}$ and $607 \mathrm{~nm}$ channels:

$$
\alpha_{\lambda_{o}}^{a e r}(r)=\frac{(d / d r)\left[\ln \frac{N_{R}(r)}{r^{2} P_{\lambda_{R}}(r)}\right]-\alpha_{\lambda_{o}}^{m o l}(r)-\alpha_{\lambda_{R}}^{m o l}(r)}{1+\left(\frac{\lambda_{o}}{\lambda_{R}}\right)}
$$

where $\alpha_{\lambda_{o}}^{a e r}(r)$ is the aerosol extinction coeffient at the laser wavelength, namely $532 \mathrm{~nm}, N_{R}(r)$ is the nitrogen molecule number density, $P_{\lambda_{R}}(r)$ is the backscattered Raman signal, at $387 \mathrm{~nm}$ in the case of nitrogen, $\alpha_{\lambda_{o}}^{m o l}(r)$ and $\alpha_{\lambda_{R}}^{m o l}(r)$ are the molecular extinction coefficients at the two involved wavelengths, $532 \mathrm{~nm}$ and $607 \mathrm{~nm}$. By the integration of the extinction coefficient at $532 \mathrm{~nm}$ one extracts the Aerosol Optical Depth, in the case of the Lidar data this is simply a summation over the atmospheric region where the aerosol presence is predominant:

$$
\begin{aligned}
A O D & =\int_{r_{1}}^{r_{2}} \alpha(r) d r \\
& =\sum_{r_{1}}^{r_{2}} \alpha(r) \Delta r
\end{aligned}
$$

\section{RESULTS}

Figures 4 shows the Aerosol Scattering Ratios (SR) for the for sites in specific days for the purpose of comparison. Since the value ranges are broad we decided for a Log scale. One can realize that the sites which show most of the larger aerosol load are Cubatão and São Paulo, both heavily industrialized or with a large urban environment, followed by Rio Claro and Bauru, respectively. Besides the larger loads do not go further than $2-3 \mathrm{~km}$, which could be indicative of a near range aerosol transport. 

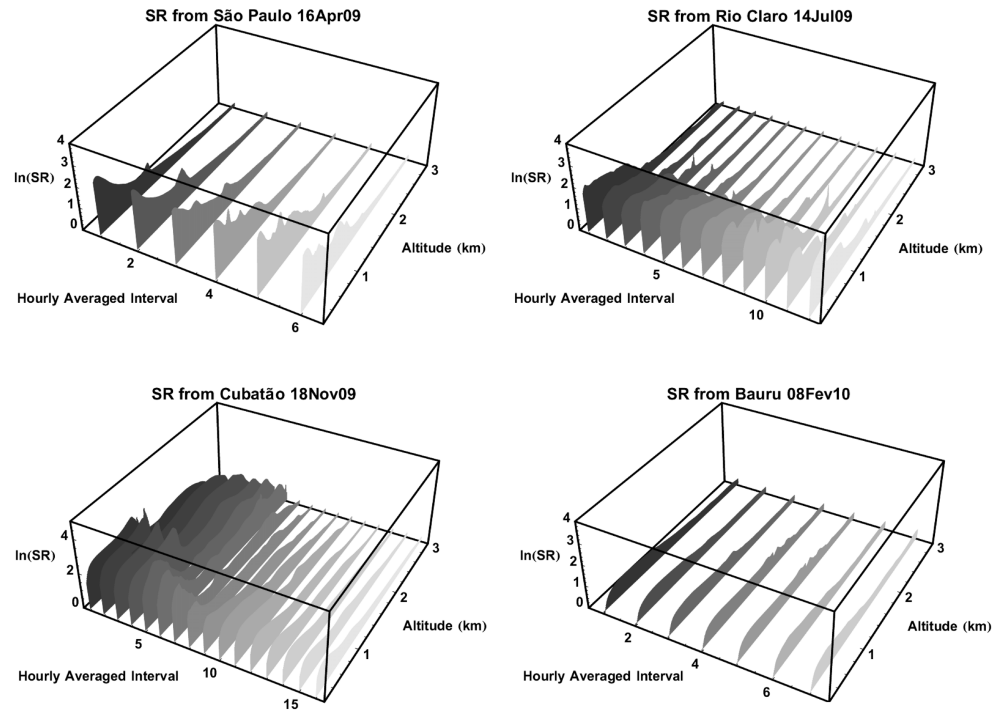

Figure 2. Aerosol Scattering Ratios for the 4 sites where the campaign took place. Their intensity are a signature of the aerosol load typical for industrialized (São Paulo and Cubatão site) and continental, rural sites (Rio Claro and Bauru).
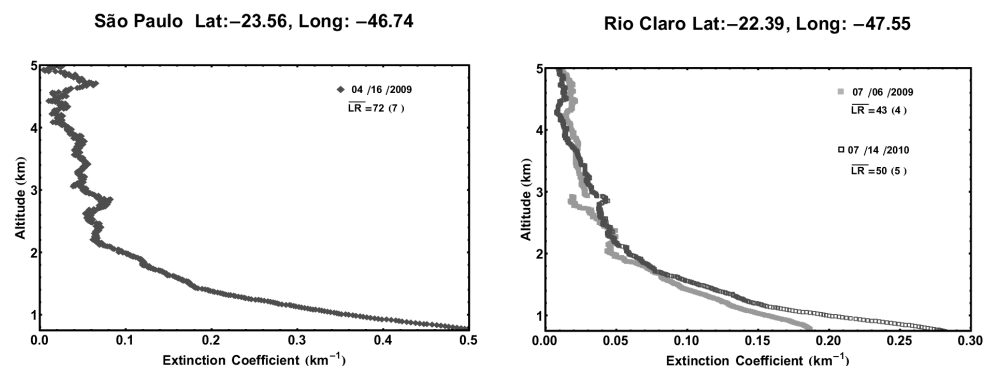

Cubatão Lat:-23.88, Long: $-\mathbf{4 6 . 4 4}$

Bauru Lat:-22.36, Long: -49.03
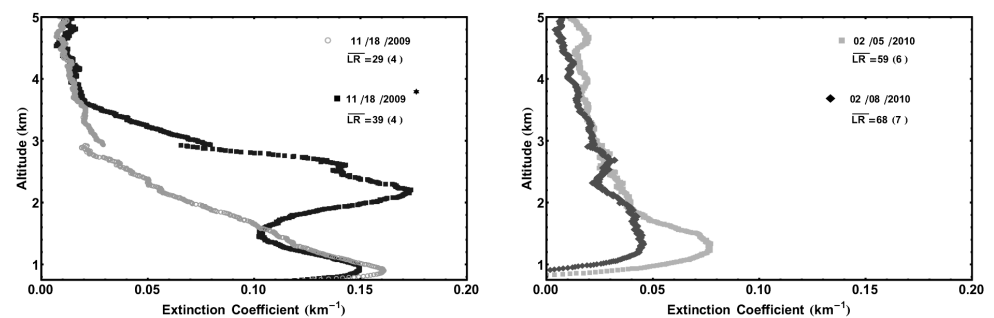

Figure 3. Some chosen days to illustrate the typical aerosol extinction profiles for each one of the sites. We also give the average Lidar Ratio (LR). In some of the examples we have for a same site more than one profile to illustrate the intrusion of industrial (Cubatão) or biomass burning plumes (Rio Claro). The LR values are summarized in Table below.

In Figure 4 we have some chosen aerosol extiction profiles taken from the elastic $(532 \mathrm{~nm})$ and Raman $(607$ $\mathrm{nm}$ ) signals. In each of them we also show the average Lidar Ratio (LR). In some of the examples we have for a same site more than one profile to illustrate the intrusion of industrial (Cubatão) or biomass burning plumes (Rio Claro).

The LR's are given for each site and are in good agreement ${ }^{22}$ with those values for urban, biomass buning and continental sites. It is intersting to observe that despite of Cubatão being an industrial site, its LR signature 
point to a maritime site. It is also given in this table the AOD values at $532 \mathrm{~nm}$ and the largest ones are for Rio Claro and São Paulo, in both cases the intrusion of plumes could well explain such high values for the days chosen.

Table 3. LR typical values for each site.

\begin{tabular}{|cccc|}
\hline \hline SITES & DATE & AOD & LR \\
\hline \hline Bauru & $08 / 02 / 10$ & $0.12(6)$ & $59(12)$ \\
\hline Bauru & $08 / 02 / 10$ & $0.09(9)$ & $68(14)$ \\
\hline Cubatão & $01 / 11 / 09$ & $0.26(6)$ & $35(7)$ \\
\hline Cubatão & $01 / 11 / 09$ & $0.33(6)$ & $35(7)$ \\
\hline Cubatão & $18 / 11 / 09$ & $0.24(4)$ & $29(8)$ \\
\hline Cubatão & $18 / 11 / 09$ & $0.34(5)$ & $39(8)$ \\
\hline Rio Claro & $06 / 07 / 09$ & $0.24(5)$ & $43(9)$ \\
\hline Rio Claro & $14 / 07 / 09$ & $0.32(6)$ & $50(10)$ \\
\hline São Paulo & $16 / 04 / 09$ & $0.63(4)$ & $72(8)$ \\
\hline
\end{tabular}




\section{CONCLUSIONS}

In the period of June through February 2010 a LIDAR observation campaign was carried in the state of São Paulo, Brazil, in order to observe and characterize optically the aerosols from two distinct sources, namely, sugar cane biomass burning and industrial emissions. For this purpose 2 LIDAR systems were available, one mobile and the other placed in a laboratory, both working in the visible $(532 \mathrm{~nm})$ and additionally the mobile system had a Raman channel available $(607 \mathrm{~nm})$. In this paper we focused on the preliminary results of the Raman LIDAR system and its derived aerosol optical quantities and obtained the Aerosol Scattering and LIDAR ratios for the fours sites which charaterized them well enough and in good agreement with those values given in the literature.

\section{Acknowledgments}

The authors would like to thank the SPIE Remote Sensing committee for the support to present this paper. Also we would like to thank the supporting agencies FAPESP, CNPq, CAPES and CNEN for providing funding for the research and scholarships to the students involved in this work and also to PETROBRAS which acquired the mobile LIDAR as part of an infrastructure project. 


\section{REFERENCES}

[1] IPCC, "Intergovernmental panel on climate change 2007: The fourth assessment report to the intergovernmental panel on climate change," tech. rep., Cambridge, New York (2007).

[2] IPCC, "Intergovernmental panel on climate change 2001: The third assessment report to the intergovernmental panel on climate change," tech. rep., Cambridge, New York (2001).

[3] Yamasoe, M. A., Kaufman, Y. J., Dubovik, O., Remer, L. A., Holben, B. N., and Artaxo, P., "Retrieval of the real part of the refractive index of aerosols from sun/sky radiometers during scar-b," Journal of Geophysical Research 103(D24) (1998).

[4] Yamasoe, M. A., Artaxo, P., Miguel, A. H., and Allen, A. G., "Chemical composition of aerosols particles from direct emissions of vegetation fires in the amazon basin: watersoluble species and trace elements," Atmospheric Environment 34 (2000).

[5] Rosenfeld, D., "Suppression of rain and snow by urban and industrial air pollution," Science $\mathbf{2 8 7}$ (2000).

[6] Dias, M. A. F. S., Artaxo, P., and Andreae, M. O., "Aerosols impact clouds in the amazon basin," GEWEX Newsletter 14(4) (2004).

[7] Lara, L. B. L. S., Artaxo, P., Martinelli, L. A., Victoria, R. L., Camargo, P. B., Krusche, A., Ayers, G. P., Ferraz, E. S. B., and Ballester, M. V., "Chemical composition of rainwater and anthropogenic influences in the Piracicaba river basin southeast brazil," Atmospheric Environment 35 (2001).

[8] Lara, L. L., Artaxo, P., Martinelli, L. A., Camargo, P. B., Victoria, R. L., and Victoria, E. S. B., "Properties of aerosol from sugar-cane burning emissions in southeastern brazil," Atmospheric Environment 39 (2005).

[9] Crutzen, P. J. and Andreae, M. O., "Biomass burning in the tropics: Impact on atmospheric chemistry and biogeochemical cycles," Science 250 (1990).

[10] Kaufman, Y. J. and Tanré, D., "Algorithm for remote sensing of tropospheric aerosol from modis," tech. rep., NASA/GSFC (1998).

[11] Boian, C. and Kirchhoff, V. W. J. H., "Measurements of CO in an aircraft experiment and their correlation with biomass burning and air mass origin in south america," Atmospheric Environment 38 (2004).

[12] Yamasoe, M. A., Randow, C. V., Manzi, A. O., Schafer, J. S., Eck, T. F., and Holben, B. N., "Effect of smoke and clouds on the transmissivity of photosynthetically active radiation inside the canopy," Atmospheric Chemistry and Physics 6 (2006).

[13] Andreae, M. O., Rosenfeld, D., Artaxo, P., Costa, A. A., Frank, G. P., Longo, K. M., and Silva-Dias, M. A. F., "Smoking rain clouds over the amazon," Science 303 (2004).

[14] Kaufman, Y. J., Tanré, D., and Boucher, O., "A satellite view of aerosols in the climate system," Nature 419 (2002).

[15] Freitas, S. R., Longo, K. M., Dias, M. A. F. S., and Artaxo, P., "Numerical modeling of air mass trajectories from the biomass burning areas of the amazon basin," Anais da Academia Brasileira de Ciências 68 (1996).

[16] Longo, K., Thompson, A. M., Kirchoff, V. W. J. H., Remer, L. A., Freitas, S. R., Dias, M. A. F. S., Artaxo, P., Hart, W., Spinhirne, J. D., and Yamasoe, M. A., "Correlation between smoke and tropospheric ozone concentrations in Cuiabá during SCAR-B," Journal of Geophysical Research 104(D10) (1998).

[17] Landulfo, E., Papayannis, A., Artaxo, P., Castanho, A. D. A., Freitas, A. Z., Souza, R. F., Junior, N. D. V., Jorge, M. P. M. P., Sánchez-CCoyllo, O. R., and Moreira, D. S. Atmospheric Chemistry and Physics 3 (2003).

[18] E. Landulfo, F. L., "Initial approach in biomass burning aerosol transport tracking with calipso and modis satellites, sunphotometer and a backscatter lidar system in brazil," in [Proceedings of SPIE - The International Society for Optical Engineering], U. N. Singh, G. P., ed., 7479, 747905, The International Society for Optical Engineering (2009).

[19] International Journal of Remote Sensing 36(13) (2005).

[20] Klett, J. D., "Inversion with variable backscatter/extinction ratios," Applied Optics 11 (1985).

[21] Ansmann, A. and Weitkamp, K., "Measurement of atmospheric aerosol extinction profiles with Raman LIDAR," Optics Letters 15, 13-18 (1990).

[22] Omar, A., Won, J.-G., Winker, D. M., Yoon, S.-C., Dubovik, O., and McCormick, M., "evelopment of global aerosol models using cluster analysis of aerosol robotic network (aeronet) measurements," Journal of Geophysical Research 110, D10S14 (2005). 